\title{
A mathematical model for evaluating the effect of wind on downward-spraying rainfall simulators
}

\author{
J.L.M.P. de Lima ${ }^{\text {a,* }}$, P.J.J.F. Torfs ${ }^{b}$, V.P. Singh ${ }^{\mathrm{c}}$ \\ ${ }^{\mathrm{a}}$ Department of Civil Engineering of the Faculty of Science and Technology (FCTUC), Institute of Marine \\ Research (IMAR), University of Coimbra, Campus 2, 3030-290 Coimbra, Portugal \\ ${ }^{\mathrm{b}}$ Department of Environmental Sciences, Wageningen Agricultural University, Nieuwe Kanaal 11, \\ 6709 PA Wageningen, The Netherlands \\ ${ }^{\mathrm{c}}$ Department of Civil and Environmental Engineering, Louisiana State University, \\ Baton Rouge, LA 70803-6405, USA
}

Received 22 December 2000; received in revised form 7 June 2001; accepted 13 June 2001

\begin{abstract}
Rainfall simulators are used to study a variety of different processes (e.g., water erosion, infiltration, overland flow, irrigation, movement of agrochemicals, etc.). Wind affects field experiments that make use of rainfall simulators. Water-drop trajectories and velocities are altered, affecting water application and kinetic energy distributions.

In this study, a three-dimensional numerical model was developed from the movement of individual drops after their release from the nozzle of a downward-spraying rainfall simulator. Drag forces, wind and gravity affect the original momentum of a single drop. Water application and kinetic energy were estimated from the coupling of a hydrodynamic model for drop movement, a drop generator representing a single full-cone spray nozzle, and an appropriate interception algorithm at the soil surface.

The mathematical model should facilitate the selection of single full-cone spray nozzles and the size and configuration of the spray area for rainfall simulation in order to achieve high application uniformity values on the plot area. It can contribute to the adequate choice of nozzles as well as operating conditions necessary for laboratory and field purposes. Laboratory and field experiments were conducted to evaluate the adequacy of the proposed methodology. (C) 2002 Elsevier Science B.V. All rights reserved.
\end{abstract}

Keywords: Numerical modelling; Rainfall simulators; Nozzles; Wind effects

\footnotetext{
* Corresponding author. Tel.: +351-239-797-183; fax: +351-239-797-179.
}

E-mail address: plima@dec.uc.pt (J.L.M.P. de Lima). 


\section{Introduction}

Field studies of natural rainfall-induced physical and chemical processes require considerable financial outlay and long observation periods (10 to 20 years) to collect sufficient information. A more cost-effective alternative is to use rainfall simulators to apply controlled rainstorms to small plots (Esteves et al., 2000; Foster et al., 2000; Lascelles et al., 2000; Kamphorst, 1987). Portable rainfall simulators used on small plots give sufficient flexibility to study a wide variety of processes (e.g., infiltration, irrigation, interrill erosion and water quality) on different soils and slopes for a wide range of land uses (Fig. 1). They also allow a number of repetitions in a short period of time.

In conducting these studies, it is important to characterize the simulated rainfall applied to the test surface. Unquestionably, wind affects field experiments that make use of devices that simulate rainfall. Many studies have been carried out that show that wind speed has a clear negative effect on uniformity in the application of water with nozzles, namely in sprinkler irrigation (Vories and von Bernuth, 1986; Von Bernuth and Seginer, 1990; Seginer et al., 1991, 1992; Tarjuelo et al., 1992, 1999b; Hans et al., 1994; Li and Kawano, 1996). Sprinkler water distribution patterns mainly depend on the design of the sprinkler itself, the size, number and configuration of nozzles, and the working pressure. Wind action must be added to this, both in speed and direction, which modifies the trajectories of the drops and jet segment, and substantially contributes to evaporation and

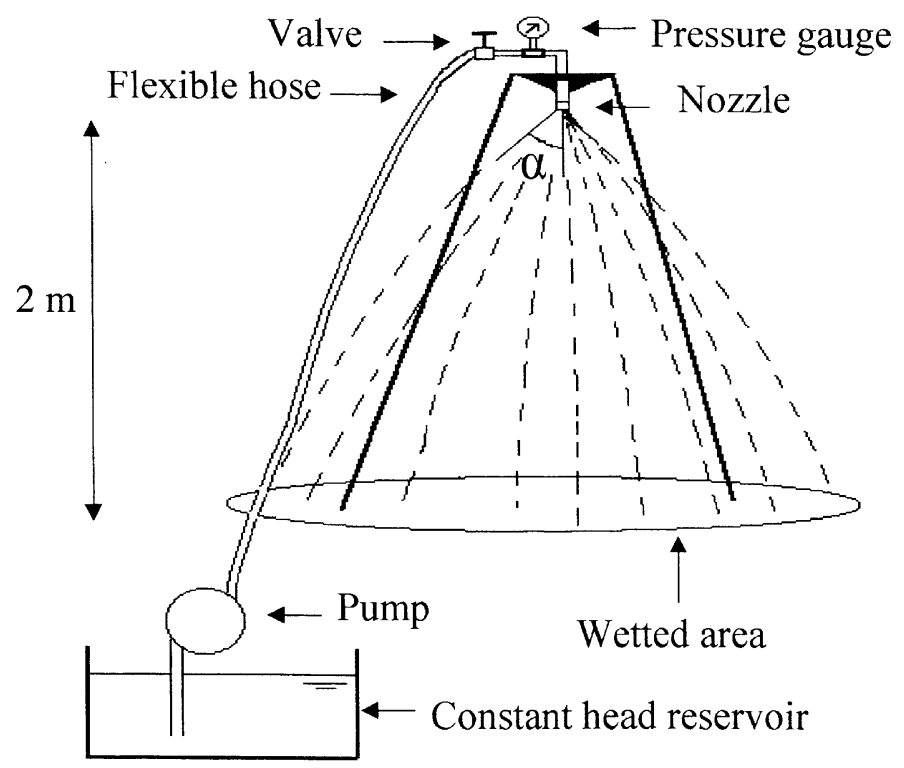

Fig. 1. Sketch of a single full-cone downward-spraying nozzle rainfall simulator. Parameter $\alpha$ is the maximum spray angle, with the vertical, of drop trajectories released by the nozzle. This set-up was used in both laboratory and field experiments. 
drift losses. Von Bernuth and Seginer (1990) showed that the distortion produced by wind in the water distribution pattern of a single-sprinkler is: a pattern lengthening in the wind direction, shifting its gravity centre roughly $1 \mathrm{~m}$ every $1 \mathrm{~m} / \mathrm{s}$ increment in wind speed towards wind direction; a pattern shortening normal to the wind direction; a reduction of the irrigated area in accordance with wind speed; and water accumulation near the sprinkler.

Investigators conducting rainfall simulations normally tend to avoid the wind problem by waiting for windless periods or by isolating the boundary of their runoff plots with windscreens. However, these procedures are not adequate for some field situations (e.g., moving storms), if they conduct their experiments under windy conditions, water-drop trajectories and velocities are altered, affecting water application and kinetic energy distributions, introducing more variables into their experimental data and making it more difficult to draw conclusions from the data set.

Spray nozzles are vital components in rainfall simulations. Different spray nozzles produce different spray patterns. Full cone sprays (solid circular pattern of drops) are commonly used in rainfall simulations. Their performance is critical to the efficiency of the system.

The main objective of this work was the study of the effect of wind on downwardspraying rainfall simulators and to present a model that should help in the selection of single or multiple (by addition) full-cone spray nozzles in order to avoid laborious fieldwork characterizing the water distribution pattern applied to a certain plot area. The mathematical model presented in this study was developed from the movement of individual drops making it feasible to study other situations (e.g., drift from a sprinkler). Laboratory and field experiments were conducted to evaluate the adequacy of the proposed methodology.

\section{Model development}

A three-dimensional numerical model was developed for the study of downwardspraying rainfall simulators, starting with the movement of individual drops after their release from the nozzle of a simulator. Drag forces, wind and gravity affect the original momentum of a single drop. Water application and kinetic energy were estimated from the coupling of a hydrodynamic model for drop movement, a drop generator representing a single full-cone spray nozzle, and an appropriate interception algorithm at the soil surface.

Two computer programs were developed: DROP, which calculates the trajectory of drops once catapulted from a nozzle, and NOZZLE, which calculates the effect of the drop hits, released from a single full-cone spray nozzle (e.g., water application and kinetic energy).

With respect to the drop size distribution produced by the nozzle, equivalent drop diameters (the quantiles) are required to describe the statistics for incorporation into the program. A function generates a "random" drop release from the nozzle where the diameter is chosen with an inverse cumulative distribution function approach. This function should be adapted to the type and characteristics of the nozzle spray. 


\subsection{Drop movement in wind}

Once drops are formed on a drop-former or catapulted from a nozzle, they begin to move under the action of gravity and frictional forces. The latter arise from their motion relative to the air, which can also be moving under wind. Okaruma and Nakanishi (1969) found, from a photographic study, that the deformation of drops in flight is random and concluded that the assumption of an average spherical shape is reasonable. The ballistics of a water drop depends on drop size, so a thorough study must consider a range of drop sizes.

For a nozzle rainfall simulator, zero wind-speed is the only situation for which twodimensional analysis is sufficient. For non-zero wind-speed, a three-dimensional model (which is symmetrical to the wind direction) must be constructed.

For the drop motion, it will be assumed that the flow under consideration is incompressible (Pruppacher and Klett, 1978). The movement of a drop is an unsteadyflow problem because of drop acceleration under the influence of gravity, a possible catapulting action (in the case of a nozzle rainfall simulator), buoyancy force, and aerodynamic force. Arguments presented elsewhere (e.g., Pruppacher and Klett, 1978) demonstrate that the effect of local fluid acceleration is negligible because of the great difference between the density of water, $\rho_{\mathrm{w}}$, and of the density of air, $\rho_{\mathrm{a}}: \rho_{\mathrm{a}} / \rho_{\mathrm{w}} \ll 1$. Hence, it is sufficient to use the steady-state drag formulas to describe the hydrodynamic resistance to the drops. In view of the above, Newton's second law of motion will be applied to the description of the velocity history of the drop, involving the drag, buoyancy, and gravity forces only. These forces must sum vectorially to equal the acceleration of the drop:

$$
\begin{aligned}
& m \frac{\mathrm{d} u_{x}}{\mathrm{~d} t}=-\frac{1}{2} \rho_{\mathrm{a}} V_{\mathrm{R}}^{2} A C_{\mathrm{D}} e_{x} \\
& m \frac{\mathrm{d} u_{y}}{\mathrm{~d} t}=-\frac{1}{2} \rho_{\mathrm{a}} V_{\mathrm{R}}^{2} A C_{\mathrm{D}} e_{y} \\
& m \frac{\mathrm{d} u_{z}}{\mathrm{~d} t}=-\frac{1}{2} \rho_{\mathrm{a}} V_{\mathrm{R}}^{2} A C_{\mathrm{D}} e_{z}+m g-\frac{\rho_{\mathrm{a}}}{\rho_{\mathrm{w}}} m g
\end{aligned}
$$

with

$$
\begin{aligned}
& e_{x}=\frac{u_{x}-w}{V_{\mathrm{R}}} ; \quad e_{y}=\frac{u_{y}}{V_{\mathrm{R}}} ; \quad e_{z}=\frac{u_{z}}{V_{\mathrm{R}}} \\
& V_{\mathrm{R}}=\sqrt{\left(u_{x}-w\right)^{2}+u_{y}^{2}+u_{z}^{2}} \\
& m=\frac{\rho_{\mathrm{w}}}{6} \pi D^{3}
\end{aligned}
$$

where $u_{x}, u_{y}$ and $u_{z}$ are the velocity components of the drop $(\mathrm{m} / \mathrm{s}), e_{x}, e_{y}$ and $e_{z}$ are the components of the unit vector giving the direction of the relative speed of the drop with respect to the wind $(\mathrm{m} / \mathrm{s}), w$ is the wind speed which is assumed to blow in the $X$-direction 
$(\mathrm{m} / \mathrm{s}), m$ is the mass of the drop $(\mathrm{kg}), \rho_{\mathrm{a}}$ and $\rho_{\mathrm{w}}$ are the densities of the air and water $(\mathrm{kg} /$ $\left.\mathrm{m}^{3}\right), A$ is the characteristic cross-section of the drop perpendicular to the relative flow $\left(\mathrm{m}^{2}\right)$, $g$ is the gravitational acceleration $\left(\mathrm{m} / \mathrm{s}^{2}\right), C_{\mathrm{D}}$ is the drag coefficient of the spherical drop, $V_{\mathrm{R}}$ is the absolute value of the relative velocity of the drop with respect to the wind $(\mathrm{m} / \mathrm{s})$, and $D$ is the drop diameter $(\mathrm{m})$.

In Eq. (3), term (I) represents the acceleration of the drop, term (II) is the drag force, term (III) is the gravity force, and term (IV) is the buoyancy force. Eqs. (1)-(3) were solved numerically. Forces acting on the drops are considered at short-time increments and interaction continues until the ground surface is reached.

The drag coefficient of a sphere was determined as a function of the drop Reynolds number (e.g., Hoerner, 1958; Williamson and Threadgill, 1974). In this study, a logarithmic wind profile above the soil surface was assumed in all cases. Wind blows in the direction of the positive $X$-axis:

$$
w=\left(\frac{u^{*}}{K}\right) \ln \frac{z_{1}}{z_{0}} \quad \text { for } z_{1}>z_{0}
$$

with

$$
u^{*}=\frac{w_{10} K}{\ln \frac{10}{z_{0}}}=\sqrt{\frac{\tau}{\rho_{\mathrm{w}}}}
$$

where $z_{0}$ is the roughness length $(\mathrm{m}), z_{1}$ is the height above the ground along the $Z_{1}$-axis, perpendicular to the surface $(\mathrm{m}), w_{10}$ is the wind speed at $10 \mathrm{~m}$ (standard measuring height at meteorological stations), $K$ is the Von Karman constant, $\tau$ is the frictional shear stress $(\mathrm{Pa})$, and $u^{*}$ is the friction velocity $(\mathrm{m} / \mathrm{s})$.

\subsection{Water application and kinetic energy distribution in wind}

The water application process with a nozzle consists of a water jet at a high velocity dispersed into the air in a set of droplets. These are then distributed over the ground surface with the aim of achieving a reasonably uniform distribution. The relatively high velocity of the jet on emission (usually over $2 \mathrm{~m} / \mathrm{s}$ ) is sufficient to produce its disintegration into droplets with inertial and viscous forces taking part in this process (Tarjuelo et al., 1999a).

Different drop sizes interact with the wind which is a major factor distorting application patterns and which also plays an important role with regard to evaporation and drift. With stronger winds worse results can be expected from the rainfall simulation and consequently of other related processes involved (e.g., overland flow).

The rainfall flux intercepted on a sloping ground depends on the angle of incidence of the rain, the inclination of the surface, and the relative orientation of the sloping surface to the rain vector (e.g., Struzer, 1972; Sharon, 1980; de Lima, 1990). Several researchers (e.g., Stillmunkes and James, 1982; Kohl et al., 1985) have indicated that soil surface sealing under sprinkler irrigation is related to the kinetic energy of the sprinkler discharge per unit area at the soil surface and to its accumulation in time. Therefore, the distribution of kinetic energy over the wetted area is also of interest. 
When the size distribution of raindrops is known, the total energy is a function of the wind velocity and, generally, of the shape of the wind profile. In the model, the velocity of each drop was calculated in accordance with the nozzle elevation and the analysis of the velocity history of falling drops (assumed to be spherical) under the influence of gravity, wind and frictional forces. The kinetic energy was summed for all drops falling on every square element of the ground surface:

$$
\mathrm{KE}=\frac{1}{2} \sum_{i=1}^{n} m_{i} u_{i}^{2}
$$

where $n$ is the number of raindrops impinging during a time interval $\Delta t$ on a section $\Delta x \Delta y$ of the horizontal plane surface, and KE is the kinetic energy of the drops falling on that section $\left(\mathrm{W} / \mathrm{m}^{2}\right)$.

The intensity of the impinging raindrops is defined by:

$$
P=\frac{\sum_{i=1}^{n} m_{i}}{\rho_{\mathrm{w}} \Delta t \Delta x \Delta y}
$$

where $P$ is the rainfall intensity $(\mathrm{m} / \mathrm{s})$.

In order to determine the difference between laboratory/field rainfall intensities and model-simulated rainfall intensities, a fitting coefficient, expressed below, was used:

$$
F_{\text {coef }}=\frac{F_{0}^{2}-F^{2}}{F_{0}^{2}}
$$

with

$$
\begin{aligned}
& F^{2}=\sum_{i=1}^{n}\left(P_{\mathrm{m}, i}-P_{\mathrm{c}, i}\right)^{2} \\
& F_{0}^{2}=\sum_{i=1}^{n}\left(P_{\mathrm{m}, i}-\sum_{i=1}^{n} \frac{P_{\mathrm{m}, i}}{n}\right)^{2}
\end{aligned}
$$

where $P_{\mathrm{m}, i}$ is the measured rainfall intensity at location $i(\mathrm{~m} / \mathrm{s})$ and $P_{\mathrm{c}, i}$ is the calculated rainfall intensity at location $i(\mathrm{~m} / \mathrm{s})$, and $n$ is the number of points used.

\section{Laboratory and field experiments}

The laboratory and field experiments used the same set-up for determining the distribution of rainfall intensity and the delimitation of the wetted area for different wind conditions, with the objective of comparing the experimental results with the numerical model. The main factors studied that influence the drop size distribution, water application and kinetic energy, using nozzles, were: working pressure, size and shape of the nozzle (e.g., Kohl, 1974; Hills and Gu, 1989; Kincaid et al., 1996), and direction and speed of 
wind (e.g., Seginer et al., 1991; de Lima and Torfs, 1994; Hans et al., 1994). However, only drop-size distribution (flower pellets method, Laws and Parsons, 1943) and water application rates were measured. The number of drops sampled for the description of the drop-size distribution was 502 (Salles et al., 1999). The kinetic energy distribution was estimated using the procedure described earlier.

Laborious catch-can tests were performed to determine the spatial distribution of water applied in laboratory and in open field conditions. A square grid of cans within the expected wetted area was used and the water volume caught by container was manually read (by precision weighing).

The equipment consisted essentially of a rainfall simulator, as shown in Fig. 1. The basic components of the simulator were: (1) one downward-oriented, continuous-spray, full-cone nozzle at a fixed pressure and height; (2) a structure which supports the nozzle, designed to be used in different slopes, both in the laboratory and in the field; and (3) connections to the pumping system and the water supply. The pumping system gives a stable pressure to avoid variations in rain intensity during the simulated rainfall event. A flexible rubberized hose distributes water from the pump to the nozzle. A pressure gauge monitors the pressure at the nozzle.

In the laboratory, the ground surface could be fixed at different slopes. A constant head tank was used as a water supply. Working pressure of the nozzles varied from 0.5 to 2.0 bar.

The field experiments were conducted in a flat agricultural land, close to the Portuguese western Atlantic coast, subjected to predominant northwestern winds. The rainfall simulator was placed away from any high vegetation or construction. Wind measurements were made continuously, with an anemometer, at a 1-m height. Water was pumped from an existing large reservoir. Working pressure of the nozzles varied from 0.5 to 1.5 bar. The wetted area under the rainfall simulator was easily recognized in the initially drier soil. The rainfall simulations were interrupted before the occurrence of overland flow.

\section{Results}

\subsection{Drop movement, water application and kinetic energy}

This section presents results of model application, namely: trajectories of drops, drop size distributions, water application and kinetic energy at ground level.

The effect of wind on drop trajectories catapulted from a nozzle in different directions is shown in Fig. 2 (two-dimensional trajectories, side view), and in Fig. 3 (three-dimensional trajectories, perspective view). In these figures, drops that are ejected against the wind do not go as far as drops sprayed downwind. Those that are sprayed crosswind have a small reduction of distance of throw crosswind, but their trajectory is translated downwind.

De Lima and Torfs (1994) have described that the greater effect of the wind on smaller drops is due primarily to greater drag. Because smaller drops have a lower fall velocity, they are also more time-subjected to the wind action. Because of this effect, the 
(a)
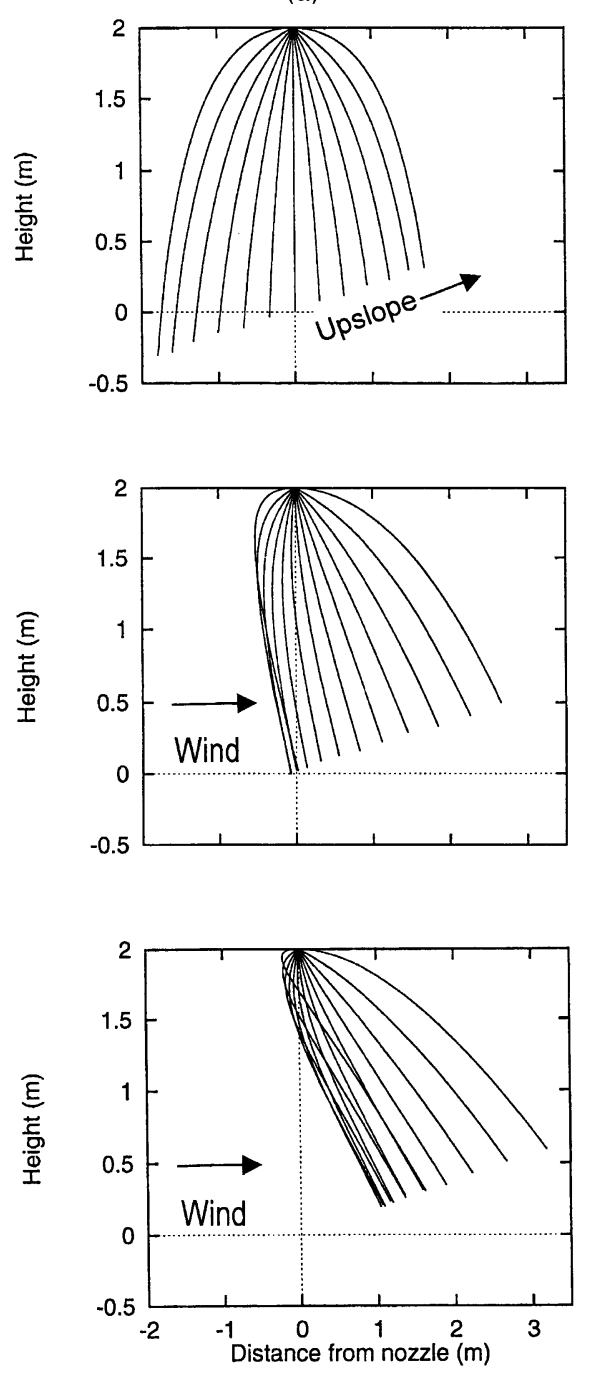

(b)
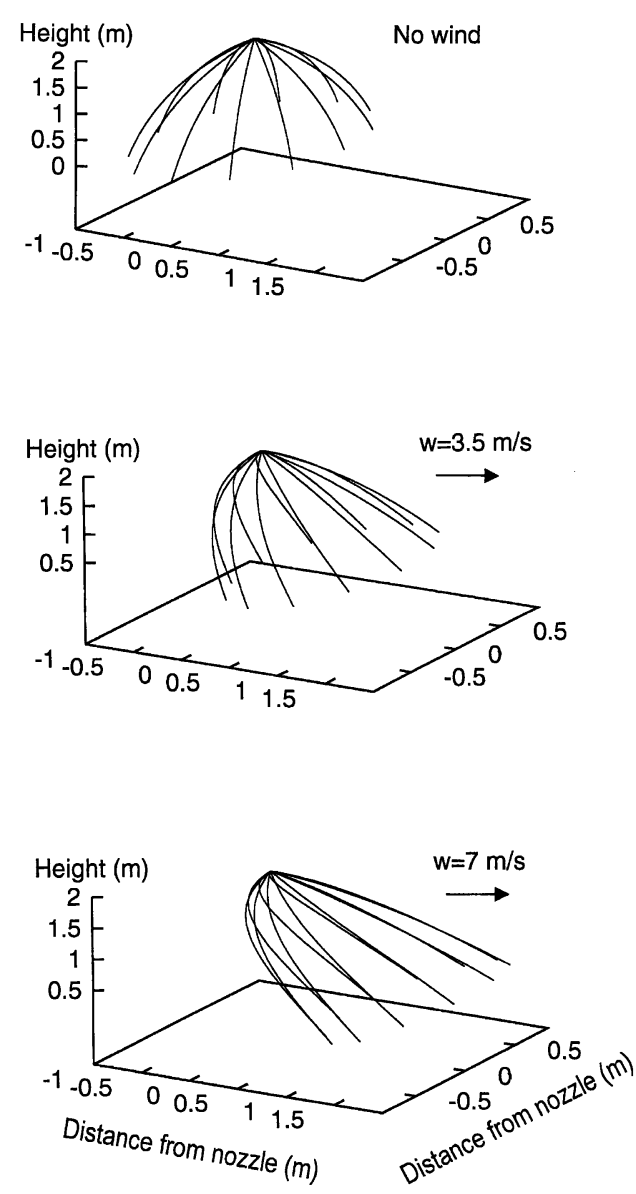

Fig. 2. (a and b) Two- and three-dimensional drop paths of a 1-mm drop ejected in different directions with a velocity of $5 \mathrm{~m} / \mathrm{s}$. Top: still air. Centre: with wind speed of $3.5 \mathrm{~m} / \mathrm{s}$ blowing upslope. Bottom: with wind speed of $7.0 \mathrm{~m} / \mathrm{s}$, also blowing upslope. The slope of the receiving plane is $10 \%$.

distribution of drop diameters is quite different for still-air and windy conditions, as shown in Figs. 3 and 4.

At the ground level, the area wetted by a nozzle, for certain working conditions, is influenced by wind and slope. If the receiving plane is horizontal, wind will cause a translation of the wetted area (Fig. 5a). Fig. 6a illustrates the effect of surface slope on the 
Diameter $(\mathrm{m})$
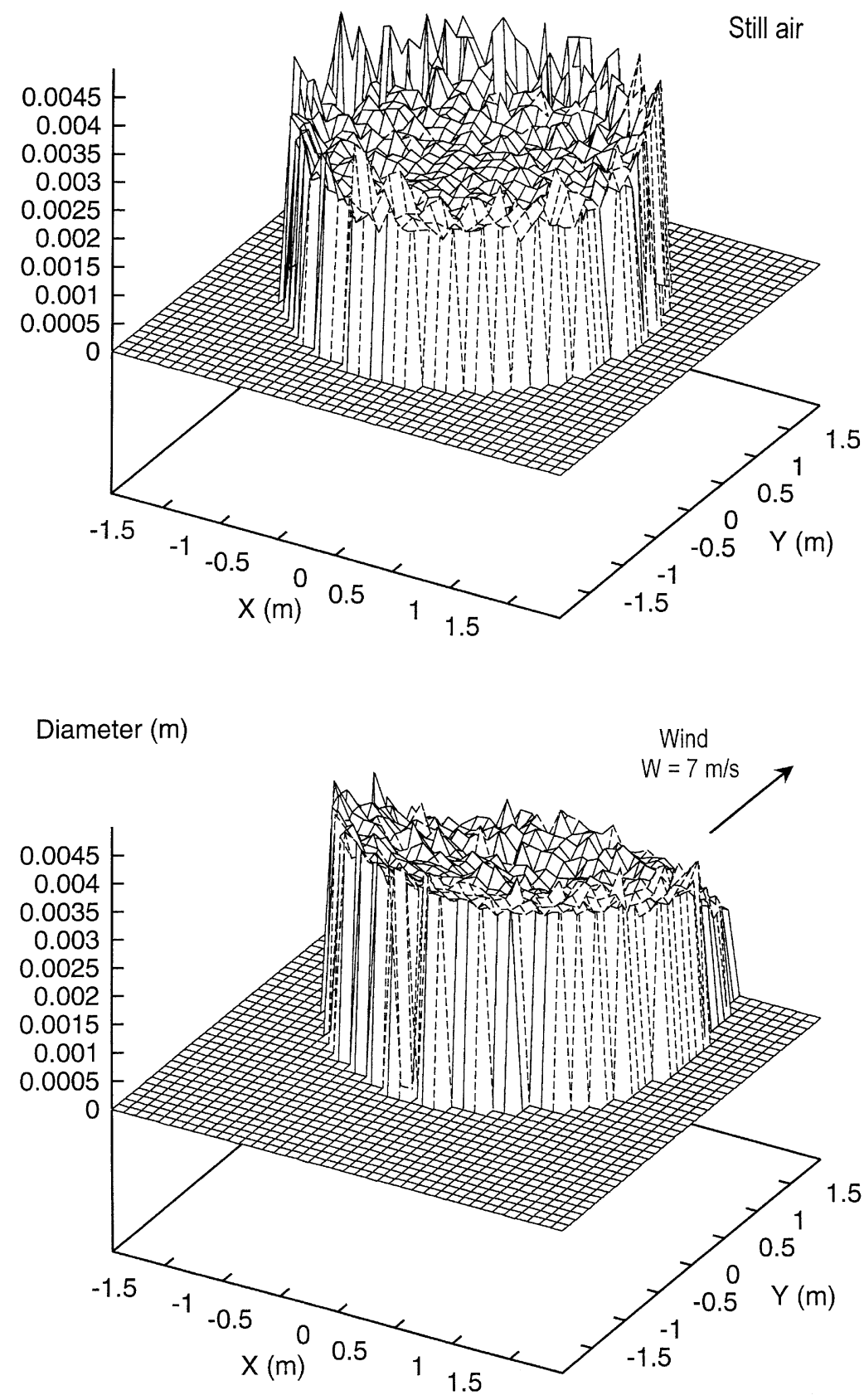

Fig. 3. Drop diameter distributions, at ground level, under a single full-cone nozzle for an increasing downslope wind. Top: still air. Bottom: with wind speed of $7 \mathrm{~m} / \mathrm{s}$ blowing downslope. The slope of the receiving plane is $10 \%$. 


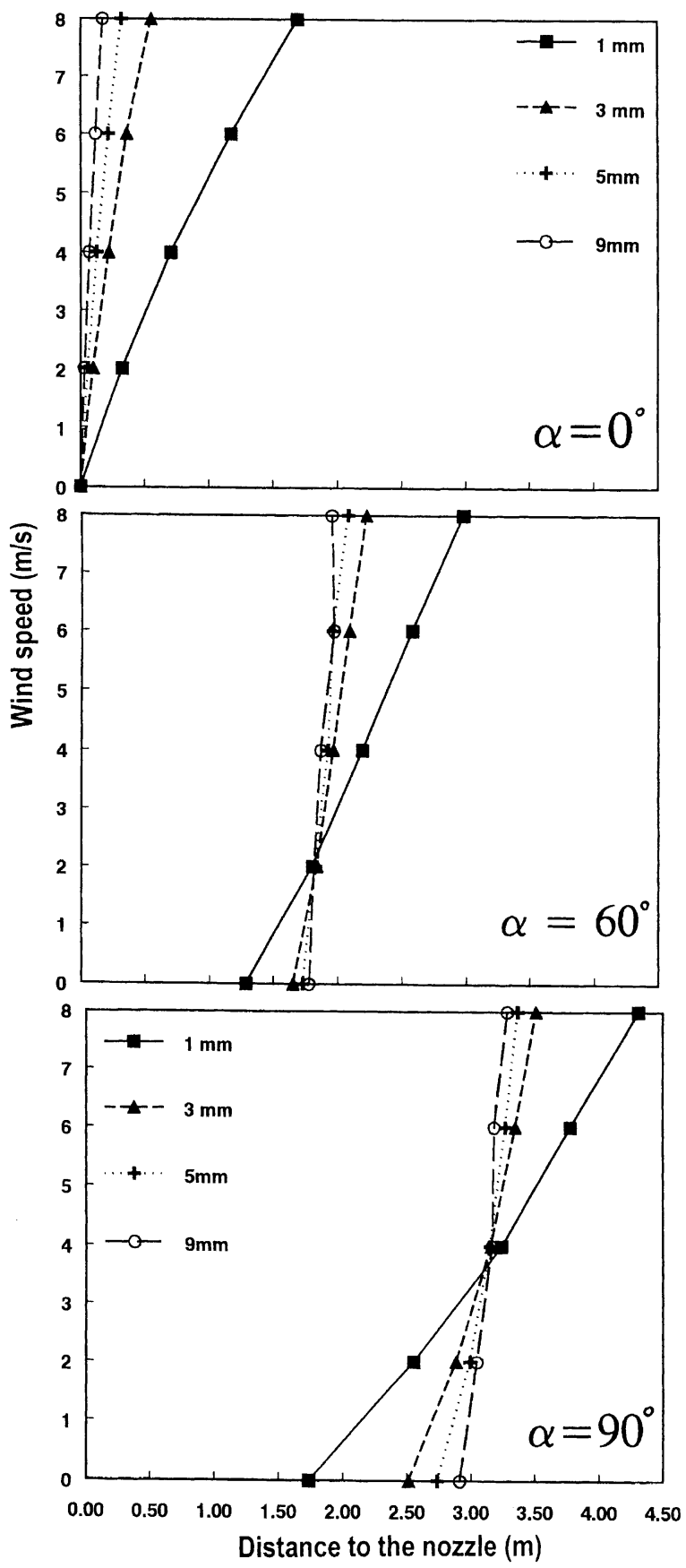

Fig. 4. Distance reached by drops $(1,3,5$ and $9 \mathrm{~mm}$ equivalent diameter) catapulted into the wind $(w=2,4,6$ and $8 \mathrm{~m} / \mathrm{s}$ ) from a nozzle, located at $2 \mathrm{~m}$ height, for different angles of ejection: $\alpha=0^{\circ}, 60^{\circ}$ and $90^{\circ}$ (see Fig. 1). 

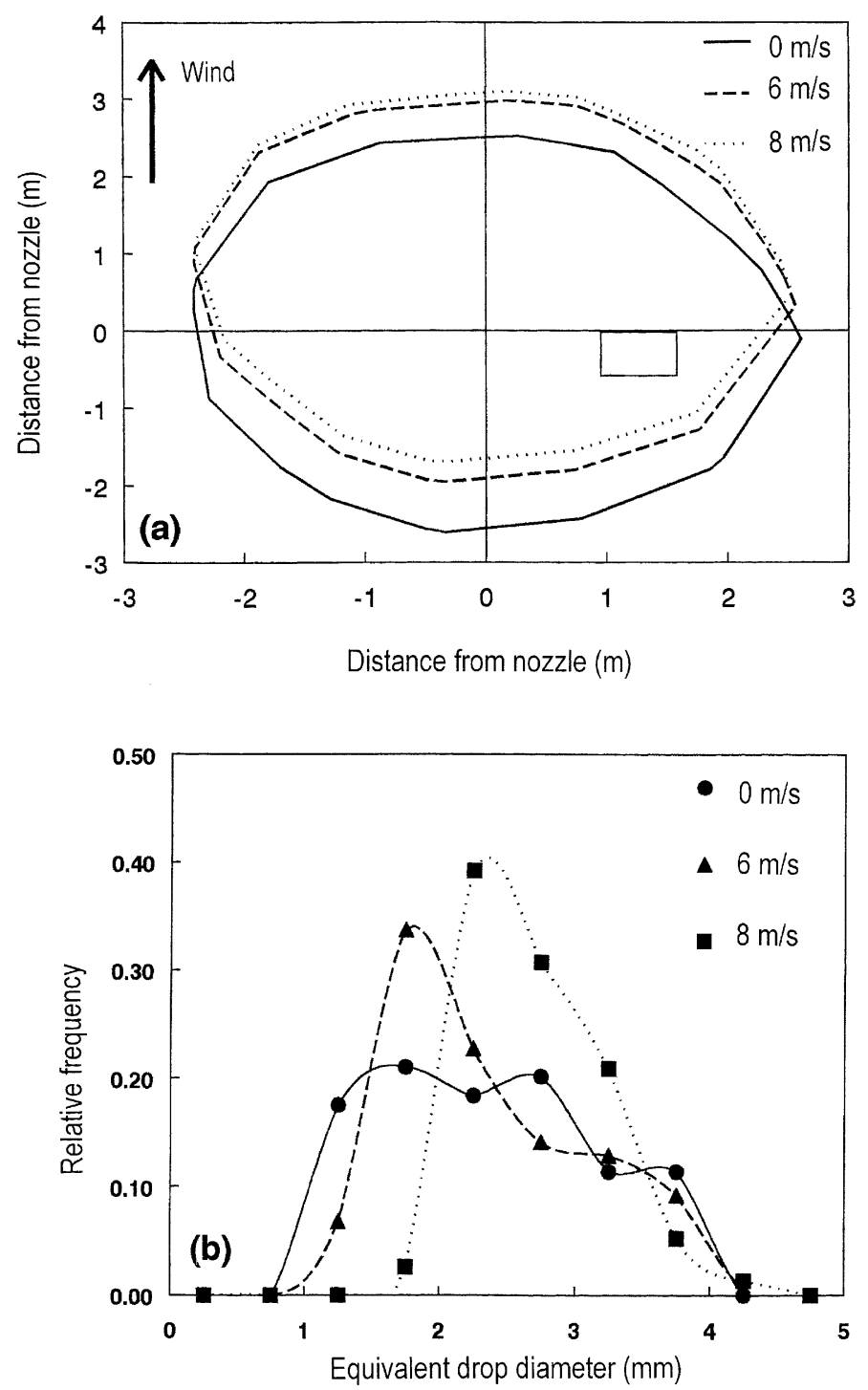

Fig. 5. Effect of wind speed ( $w=0,6$ and $8 \mathrm{~m} / \mathrm{s}$ ) for a horizontal receiving surface and a maximum ejection angle $\alpha=90^{\circ}$ : (a) Wetted areas under a single full-cone nozzle spray located at $2 \mathrm{~m}$ height, and (b) drop size distribution under the nozzle, for drops intercepted in the rectangular areas observed in (a), for different wind speeds. Drops are ejected at a velocity of $5 \mathrm{~m} / \mathrm{s}$.

wetted area for a certain constant wind speed. In this case, where the wind is blowing upslope, the wetted area is substantially reduced for steeper surface slopes. In Figs. $5 \mathrm{~b}$ and $6 \mathrm{~b}$, an analysis is made of drop size distributions that are intercepted in a rectangular area represented, respectively, in Figs. 5a and 6a, for the two situations described. Wind strongly affects smaller drops and, consequently, for higher wind speeds, the rectangular 
area receives drops with larger drop diameters (Fig. 5). Fig. 6b shows the combined effect of wind and slope, on drop size distributions.

Kinetic energy under a nozzle, both in still-air and in wind, is normally highly concentrated as observed in the peaks shown in Figs. 7 and 8. These figures illustrate
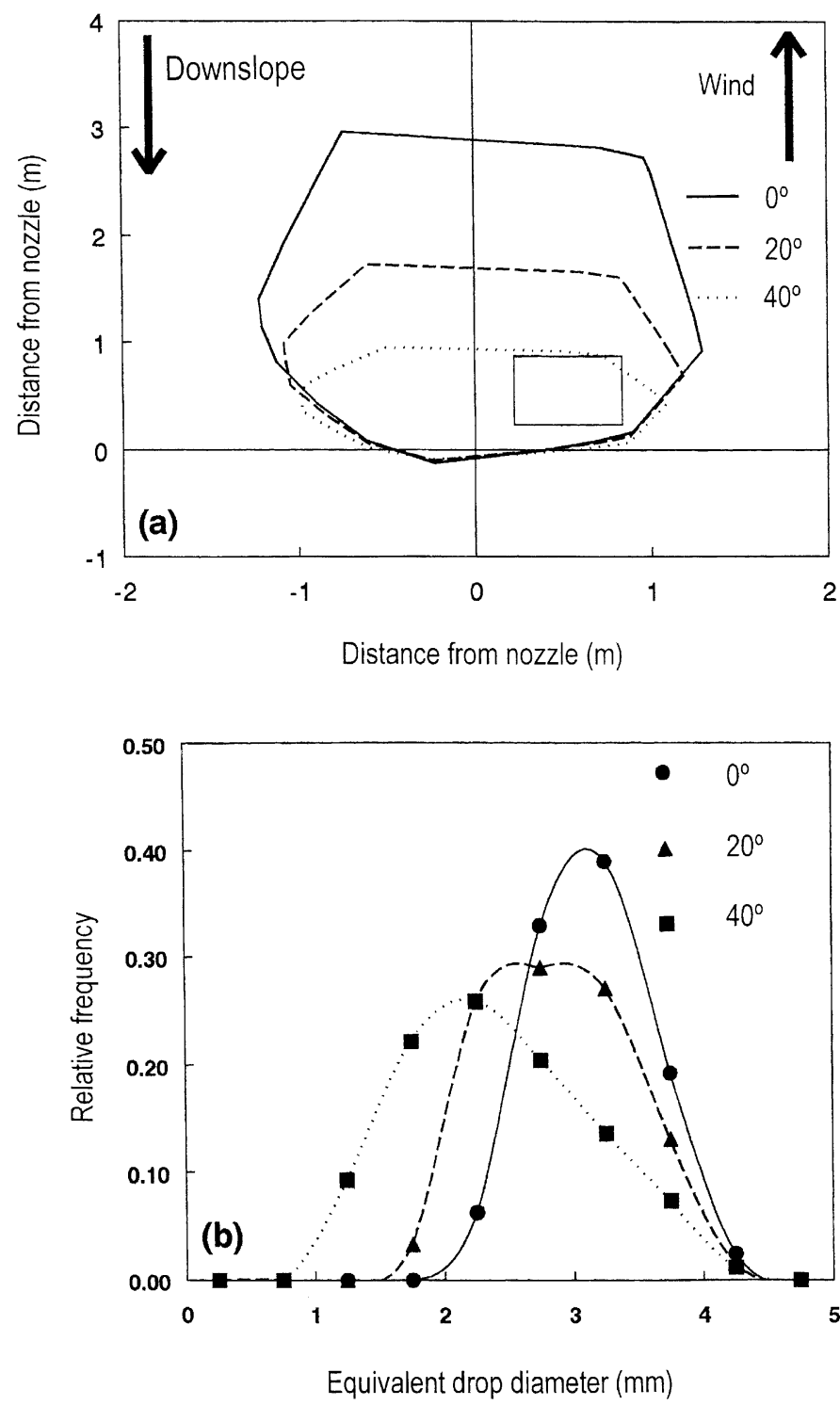

Fig. 6. Effect of slope $\left(\alpha_{\text {Surface }}=0^{\circ}, 20^{\circ}\right.$ and $\left.40^{\circ}\right)$ for a constant wind of $7 \mathrm{~m} / \mathrm{s}$, blowing upslope, and a maximum ejection angle $\alpha=50^{\circ}$ : (a) Wetted areas under a single full-cone nozzle spray located at $2 \mathrm{~m}$ height, and (b) drop size distribution under the nozzle, for drops intercepted in the rectangular areas observed in (a), for different slopes of the receiving plane (ground surface). Drops are ejected at a velocity of $5 \mathrm{~m} / \mathrm{s}$. 
KE (watts $\left./ \mathrm{m}^{2}\right)$
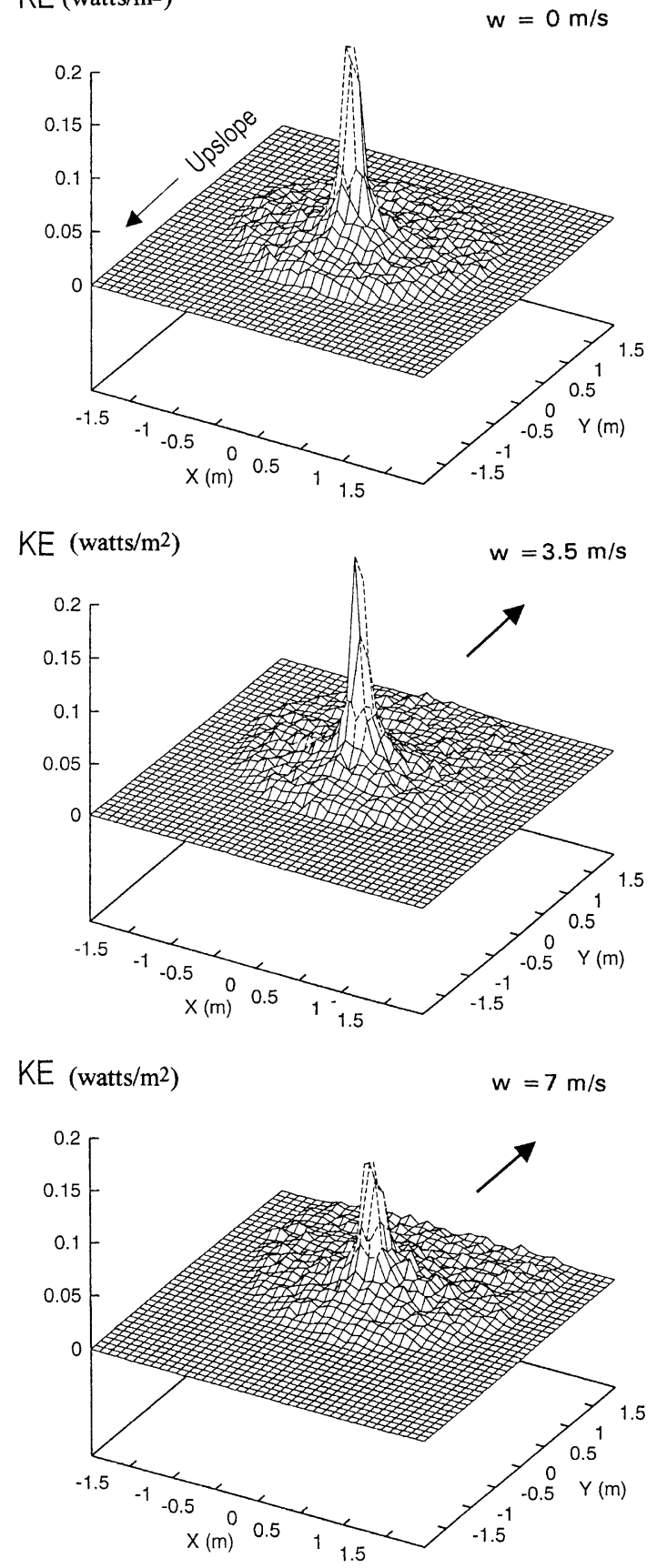

Fig. 7. Kinetic energy under a single full-cone nozzle spray for different wind velocities ( $w=0,3.5$ and $7 \mathrm{~m} / \mathrm{s})$. The slope of the receiving plane is $10 \%$. 

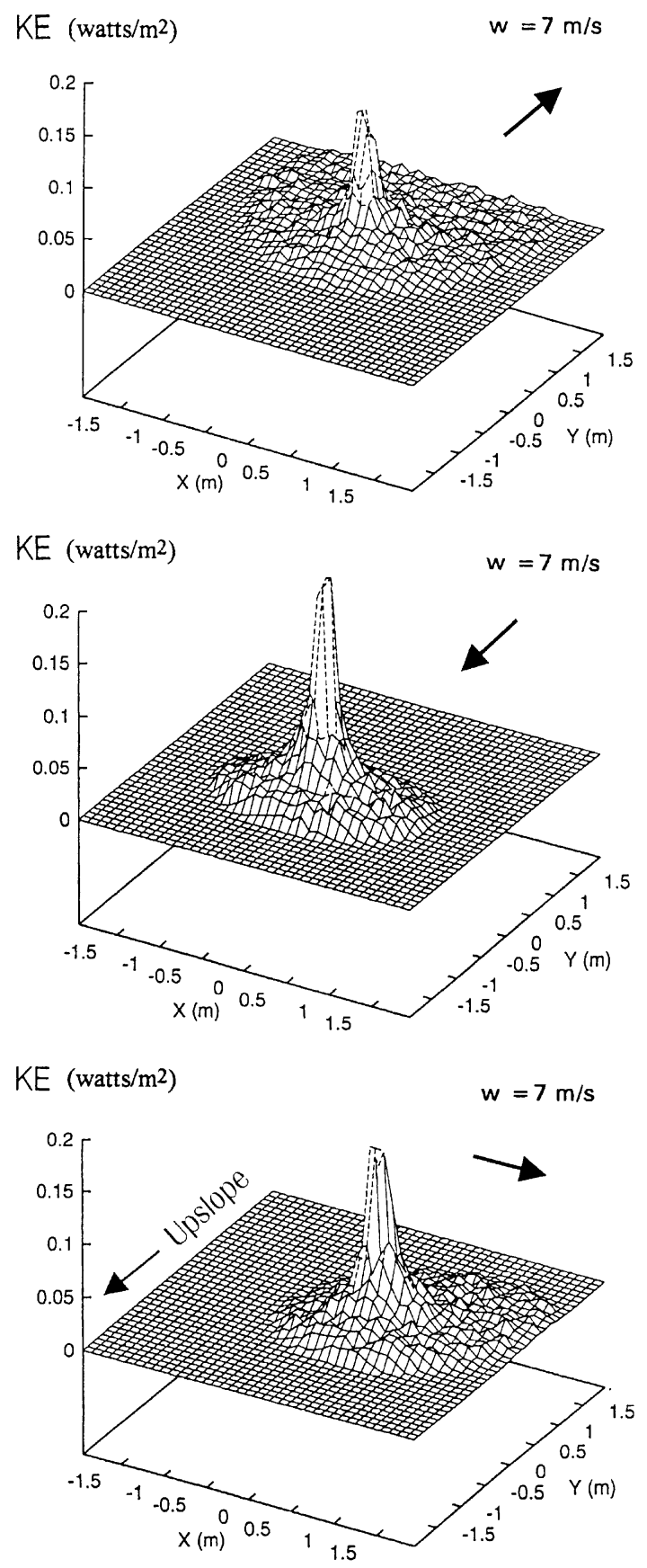

Fig. 8. Kinetic energy under a single full-cone nozzle for different wind directions. Top: with wind blowing downslope. Centre: with wind blowing upslope. Bottom: with wind blowing from the left. The wind speed is $w=7 \mathrm{~m} / \mathrm{s}$, the slope of the receiving plane is $10 \%$ and the maximum spray angle is $100^{\circ}$ (see Fig. 1). 
the effect of wind intensity (Fig. 7) and direction (Fig. 8) on kinetic energy, which is closely related to water application at ground level. In all cases, regardless of the shift and distortion of the wetted area, there remains a strong concentration of kinetic energy below the nozzle, or close by below the nozzle, characteristic of sprays formed by a solid circular pattern of drops.

Most rainfall simulations require a minimum value of water distribution uniformity $\mathrm{CU} \geq 80 \%$, where CU (Christiansen, 1942) is defined by:

$$
\mathrm{CU}=100\left(1-\frac{\sum_{i=1}^{n}\left|P_{i}-\bar{P}\right|}{\sum_{i=1}^{n} P_{i}}\right)
$$

where CU is the Christiansen's coefficient of uniformity $(\%), P_{\mathrm{i}}$ is the rainfall intensity or water application depth at location $i(\mathrm{~m} / \mathrm{s}), \bar{P}$ is the mean rainfall intensity $(\mathrm{m} / \mathrm{s})$ and $n$ is the number of observation points. Low values of CU are usually indicators of a faulty combination of the size of plot, type, number and spacing of nozzles and working pressure or windy conditions.

\subsection{Comparison of numerical and experimental results}

This section presents a comparison of numerical and experimental results. The experiments were carried out with a single full cone nozzle spray, both in the laboratory and in the field.

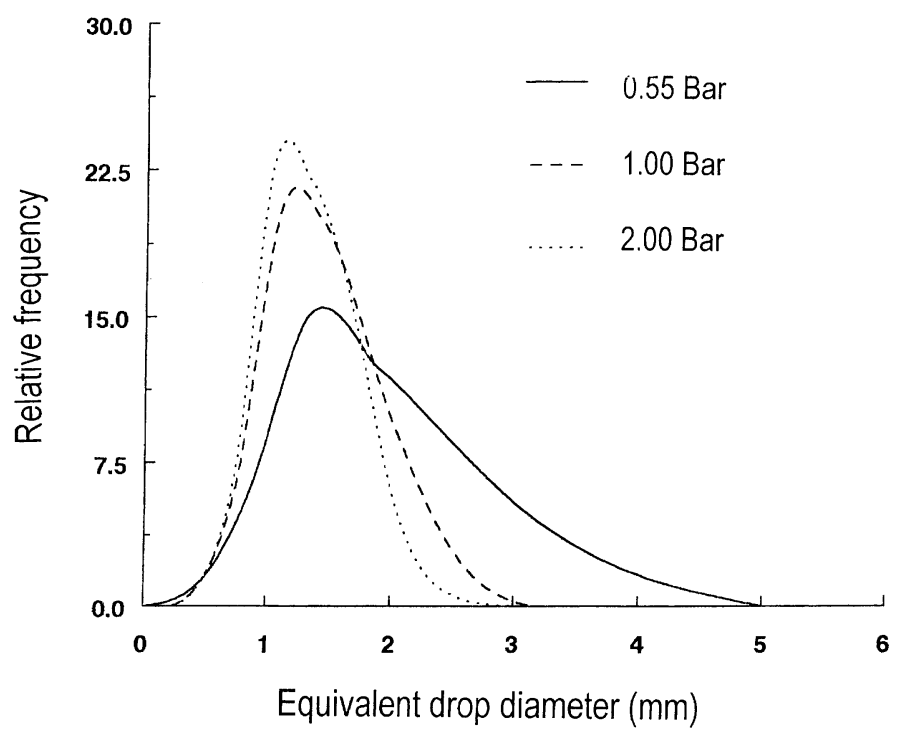

Fig. 9. Measured drop size distributions, under the nozzle, located at $2 \mathrm{~m}$ height, for working pressures of $0.55,1$ and 2 bar. 


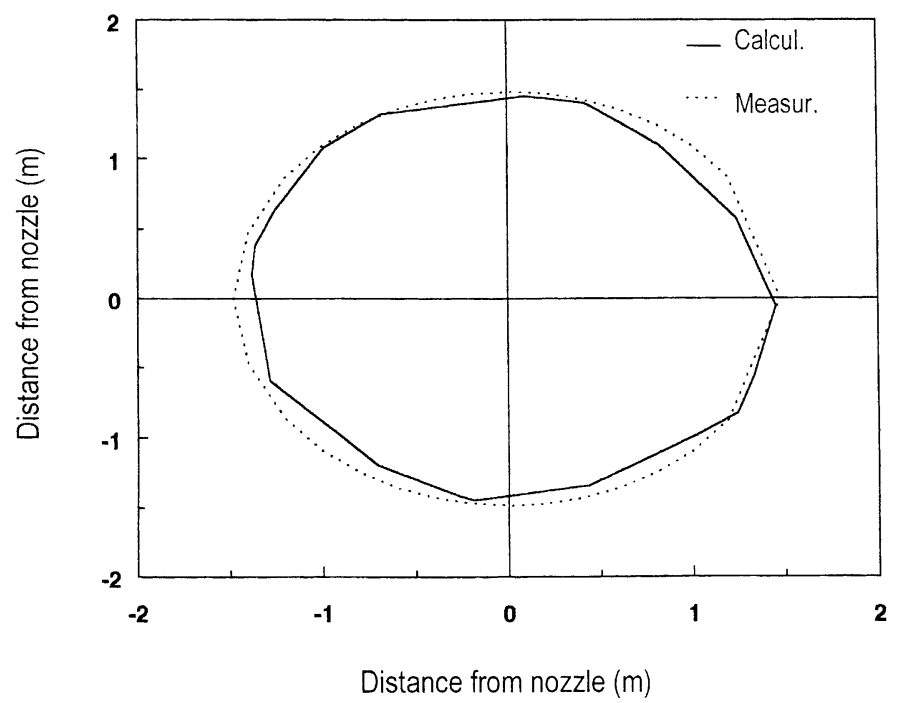

Fig. 10. Comparison of calculated and measured wetted areas for still air (laboratory) conditions. The receiving surface was horizontal. The nozzle, positioned at $(0,0)$ location at $2 \mathrm{~m}$ height, had a working pressure of $1.5 \mathrm{bar}$.

The first step was the determination of the nozzle characteristics (total discharge, maximum spray angle and drop size distribution), which were also used as input data for the numerical model. It should be noted that these characteristics are dependent on the nozzle

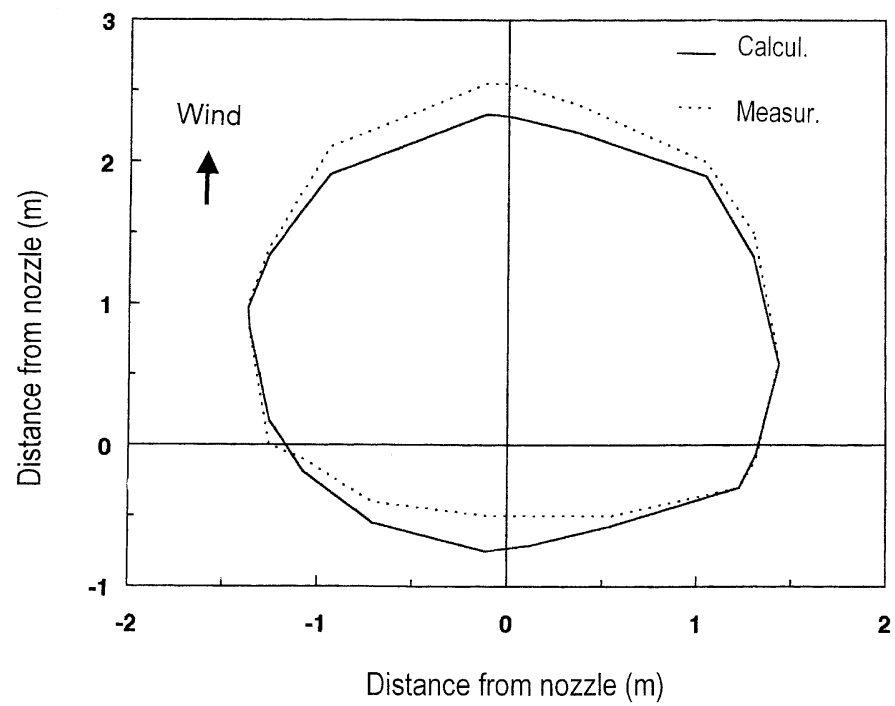

Fig. 11. Comparison of calculated and measured wetted areas for windy (field) conditions. The receiving surface was horizontal. Wind speed was $6.5 \mathrm{~m} / \mathrm{s}$. The nozzle, positioned at $(0,0)$ location at $2 \mathrm{~m}$ height, had a working pressure of 1.5 bar. 

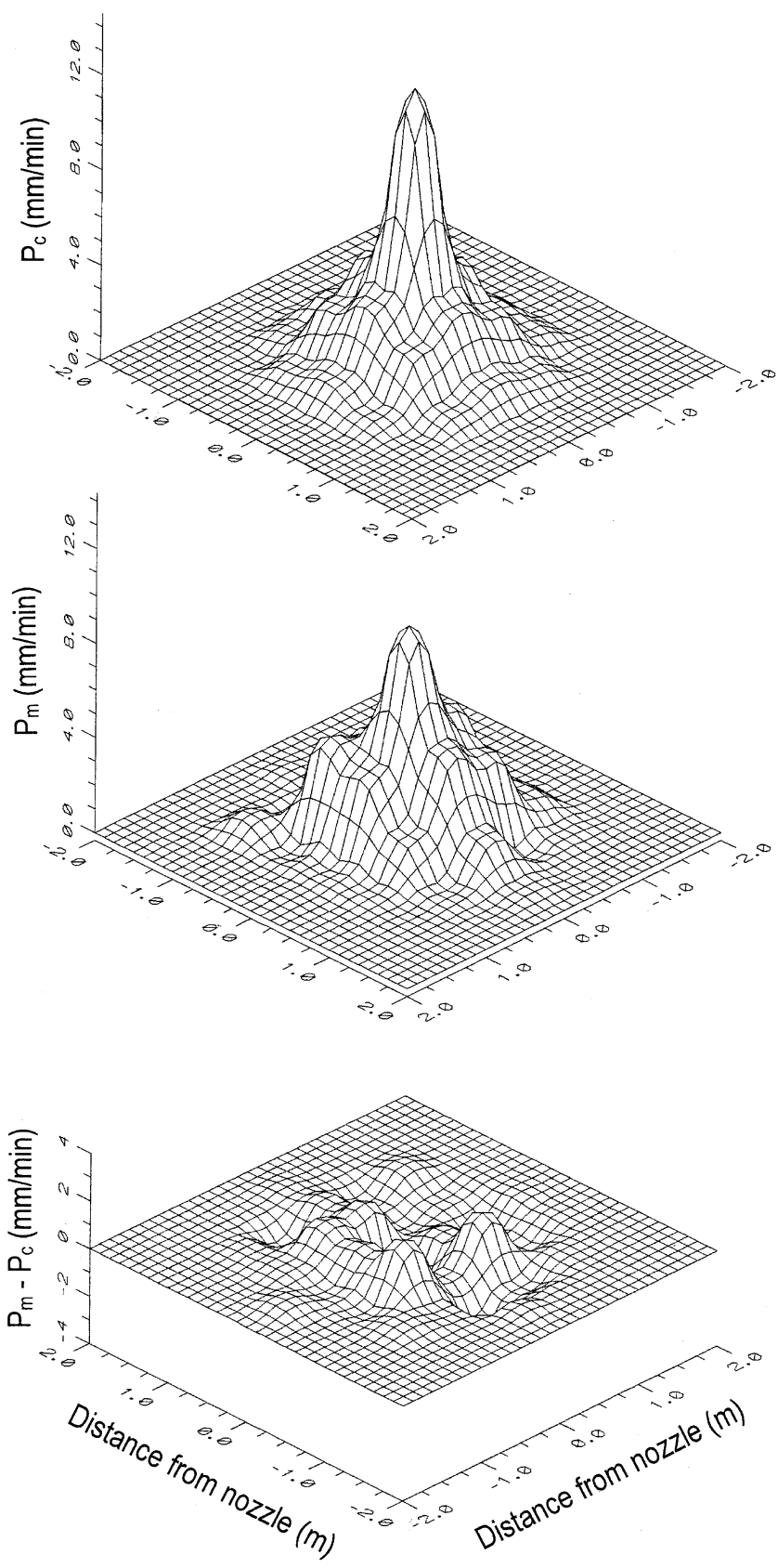

Fig. 12. Comparison of calculated and measured rainfall intensity distribution for no-wind conditions. The receiving surface was horizontal. The nozzle, positioned at $(0,0)$ location at $2 \mathrm{~m}$ height, had a working pressure of 1.5 bar. 

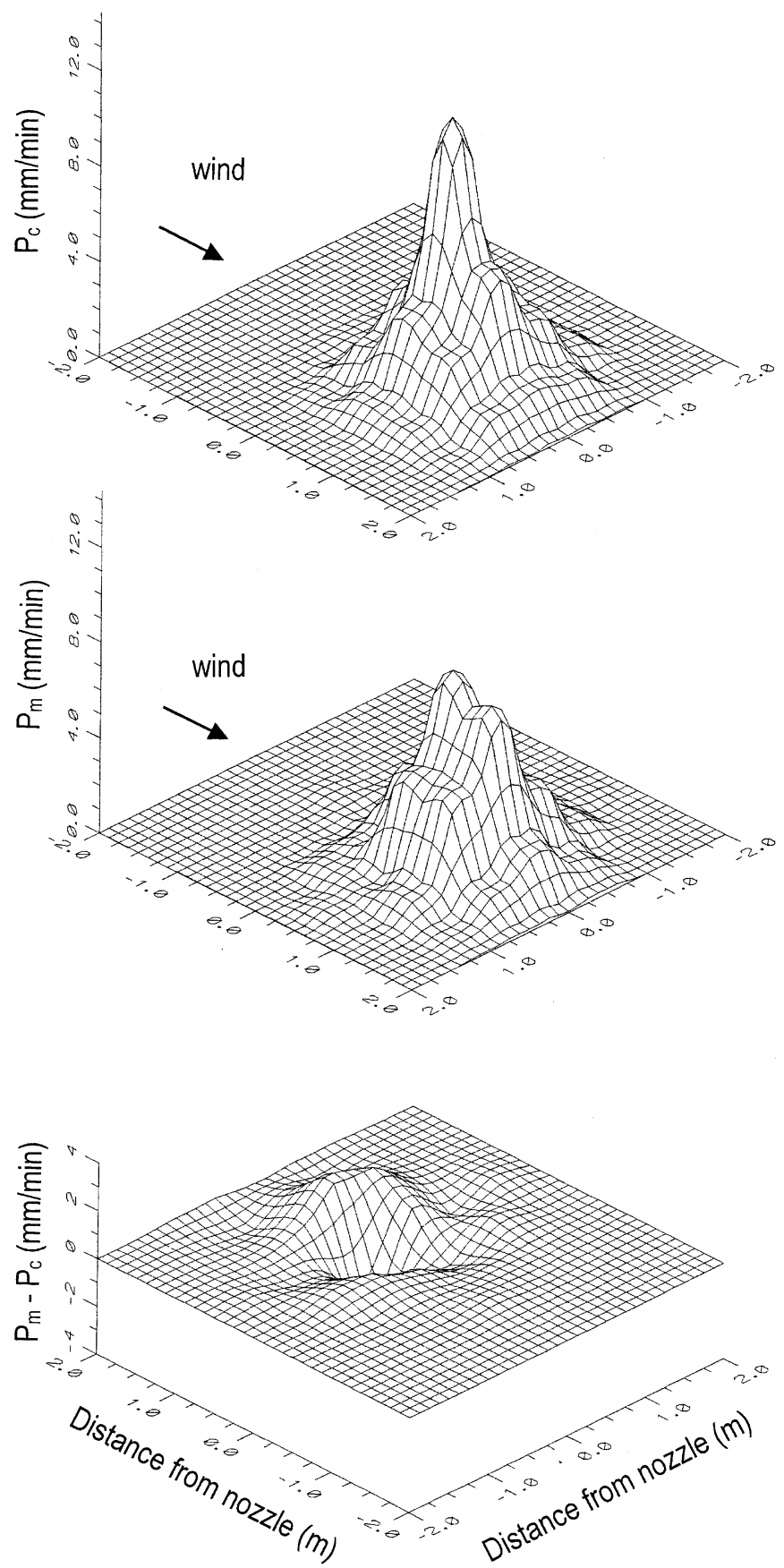

Fig. 13. Comparison of calculated and measured rainfall intensity distribution for a $6.5-\mathrm{m} / \mathrm{s}$ wind velocity. The receiving surface was horizontal. The nozzle, positioned at $(0,0)$ location at $2 \mathrm{~m}$ height, had a working pressure of 1.5 bar. 
Table 1

Fitting coefficients $\left(F_{\text {coef }}\right)$ for laboratory and field experiments

\begin{tabular}{lllll}
\hline $\begin{array}{l}\text { Type of } \\
\text { experiment }\end{array}$ & $\begin{array}{l}\text { Wind speed, } \\
w(\mathrm{~m} / \mathrm{s})\end{array}$ & $\begin{array}{l}\text { Nozzle working } \\
\text { pressure, } p(\mathrm{bar})\end{array}$ & $\begin{array}{l}\text { Fitting } \\
\text { coefficient, } F_{\text {coef }}\end{array}$ & $\begin{array}{l}\text { Number of } \\
\text { points used, } n\end{array}$ \\
\hline Laboratory & Still air & 0.5 & 0.86 & 28 \\
& & 1.0 & 0.82 & 37 \\
& & 1.5 & 0.77 & 37 \\
Field & \multirow{3}{*}{3.0} & 0.5 & 0.78 & 27 \\
& & 1.0 & 0.86 & 27 \\
& 1.5 & 0.71 & 32 \\
& 0.5 & 0.85 & 26 \\
& 1.0 & 0.84 & 29 \\
\end{tabular}

used and on the working pressure. For example, Fig. 9 presents the drop size distribution produced by the nozzle operating at three pressures: 0.55, 1 and 2 bar (de Lima, 1997).

Results are available for still air (laboratory conditions) and for two wind velocities (field conditions): 3.0 and $6.5 \mathrm{~m} / \mathrm{s}$ (measured at $1 \mathrm{~m}$ of height).

The differences between calculated and observed wetted areas (delimited with border line) were quite small for both laboratory and field conditions, as shown in the examples presented in Figs. 10 and 11. The numerical model is able to predict the changes in the wetted area induced by wind. However, bigger differences are observed with wind (Fig. 11). The wind speed, the maximum spray angle and the slope of the surface influence the wetted area under the spraying system. In the case of horizontal ground surface, wind induces a translation of the wetted area in the direction of the wind (Fig. 11).

Figs. 12 and 13 and Table 1 show some results where the measured rainfall intensities at the ground level, with and without wind, were compared with the numerical results.

In Table 1, the fitting coefficient $F_{\text {coef }}$ was determined using Eqs. (11)-(13).

For this experiments, just below the nozzle, the measured rainfall intensity is usually smaller than the calculated simulated rainfall (Figs. 12 and 13). Also, the differences between calculated and observed rainfall intensities increase with nozzle working pressure and wind speed.

\section{Conclusions}

Many factors affect water application uniformity under spraying systems, including nozzle type, pressure, and environmental conditions (e.g., wind). In this study, the effect of wind on nozzle sprays was investigated, using a numerical model. The results show that wind has a significant effect on rainfall simulations. The following conclusions can be drawn.

(i) Drop size distributions with and without wind differ considerably, because the trajectories of smaller drops are more affected by wind than those of bigger drops. Water application and kinetic energy distributions can be studied by coupling a hydrodynamic model for drop movement and an appropriate drop generator. 
(ii) The mathematical model presented should facilitate the selection of single full-cone spray-nozzles characteristics (i.e., spray angles, ejection velocities and drop-size distribution) and of the size and configuration of the spray area for expected field situations (e.g., rainfall characteristics, wind conditions, slope of terrain and plot size), in order to achieve high application uniformity values on the plot area. It provides a simple way of visualizing spray patterns on different sloping surfaces and for different wind conditions. It can contribute to the adequate choice of nozzles as well as operating conditions, necessary for laboratory and field purposes.

Further research should focus on the coupling of the models presented with an overland flow model. Future field experiments should also test relationships for a wider range of conditions (e.g., other nozzles, issues such as spray drift, etc.).

\section{Acknowledgements}

This study was partly supported by the Portuguese Foundation for Science and Technology (Project FCT/MCT-SAPIENS POCTI/1999/MGS/35661). Experimental results were partly conducted by M.A.C. Nunes during the preparation of his Master of Science Thesis at the Department of Civil Engineering of the Faculty of Science and Technology of the University of Coimbra, under the supervision of the first author.

\section{References}

Christiansen, J.E., 1942. Irrigation by sprinkling. California Agricultural Experiment Station Bulletin 670. University of California, Berkeley, CA.

de Lima, J.L.M.P., 1990. The effect of oblique rain on inclined surfaces: a monograph for the rain-gauge correction factor. J. Hydrol. 115, 407-412.

de Lima, J.L.M.P., 1997. Modelação de simuladores de chuva com nebulizadores de cone preenchido. Acta do $3^{\circ}$ Simpósio de Hidráulica e Recursos Hídricos dos Países de Língua Oficial Portuguesa ( $3^{\text {a }}$ SILUSBA), APRH/ AMCT/ABRH, 15-17 de Abril de 1997, Maputo, Moçambique, Vol. II, 10 pp. (in Portuguese).

de Lima, J.L.M.P., Torfs, P.J.J.F., 1994. Effects of wind on simulated rainfall and overland flow under single fullcone nozzle sprays. In: Trakiris, G., Santos, M.A. (Eds.), Proceedings of the Second European Conference on Advances in Water Resources Technology and Management. Balkema, Lisbon, Portugal, pp. 443-450.

Esteves, M., Planchon, O., Lapetite, J.M., Silvera, N., Cadet, P., 2000. The "EMIRE" large rainfall simulator: design and field testing. Earth Surf. Processes Landforms 25, 681-690.

Foster, I.D.L., Fullen, M.A., Brandsma, R.T., Chapman, A.S., 2000. Drip-screen rainfall simulators for hydro- and pedo-geomorphological research: the coventry experience. Earth Surf. Processes Landforms 25, 691-707.

Hans, S., Evans, R.G., Kroeger, M.W., 1994. Sprinkler distribution patterns in windy conditions. Trans. ASAE 37 (5), $1481-1489$.

Hills, D., Gu, Y., 1989. Sprinkler volume mean droplet diameter as a function of pressure. Trans. ASAE 32 (2), $471-476$.

Hoerner, S.F., 1958. Dynamics. University Tutorial Press, London.

Kamphorst, A., 1987. A small rainfall simulator for the determination of soil erodibility. Neth. J. Agric. Sci. 35, 407-415.

Kincaid, D.C., Solomon, K.H., Oliphant, J.C., 1996. Drop size distributions for irrigation sprinklers. Trans. ASAE 39 (3), 839-845.

Kohl, R.A., 1974. Drop size distribution from medium-sized agricultural sprinklers. Trans. ASAE 17 (4), $690-693$. 
Kohl, R.A., Deboer, D.W., Evenson, P.D., 1985. Kinetic energy of low pressure spray sprinklers. Trans. Am. Soc. Agric. Eng. 28 (5), 1526-1529.

Lascelles, B., Favis-Mortlock, D.T., Parsons, A.J., Guerra, A.J.T., 2000. Spatial and temporal variation in two rainfall simulators: implications for spatially explicit rainfall simulation experiments. Earth Surf. Processes Landforms 25, 709-721.

Laws, J.O., Parsons, D.A., 1943. Relation of raindrop size to intensity. Trans. Am. Geophys. Union 24, $452-459$.

Li, J., Kawano, H., 1996. Sprinkler rotation nonuniformity and water distribution. Trans. ASAE 39 (6), 2027-2031.

Okaruma, S., Nakanishi, K., 1969. Theoretical study on sprinkler sprays (part four) geometric pattern form of single sprayer under wind conditions. Trans. Jpn. Soc. Irrig. Drain. Reclam. Eng. 29, 35-43.

Pruppacher, H.R., Klett, J.D., 1978. Microphysics of Clouds and Precipitation. Reidel, Dordrecht.

Salles, C., Poesen, J., Borselli, L., 1999. Measurement of simulated drop size distribution with an optical spectro pluviometer: sample size considerations. Earth Surf. Processes Landforms 24, 545-556.

Seginer, I., Nir, D., von Bernuth, R.D., 1991. Simulation of wind-distorted sprinkler patterns. J. Irrig. Drain. Eng., ASCE 117 (2), 285-306.

Seginer, I., Kantz, D., Ni, D., von Bernuth, R.D., 1992. Indoor measurement of single-radius sprinkler patterns. Trans. ASAE 35 (2), 523-533.

Sharon, D., 1980. The distribution of hydrologically effective rainfall incident on sloping ground. J. Hydrol. 46, $165-188$

Stillmunkes, R.T., James, L.G., 1982. Impact energy of water droplets from irrigation sprinklers. Trans. ASAE 25 (1), $130-133$.

Struzer, L.R., 1972. Problem of determining precipitation falling on mountain slopes. Sov. Hydrol. Sel. Pap. 2, $129-142$.

Tarjuelo, J.M., Valiente, M., Lozoya, J., 1992. Working conditions of a sprinkler to optimize the application of water. J. Irrig. Drain. Eng., ASCE 118 (6), 895-913.

Tarjuelo, J.M., Montero, J., Valiente, M., Honrubia, F.T., Ortiz, J., 1999a. Irrigation uniformity with medium size sprinklers: Part I. Characterization of water distribution in no-wind conditions. Trans. ASAE 42 (3), 665-675.

Tarjuelo, J.M., Montero, J., Carrión, P.A., Honrubia, F.T., Calvo, M.A., 1999b. Irrigation uniformity with medium size sprinklers: Part II. Influence of wind and other factors on water distribution. Trans. ASAE 42 (3), 677-689.

Von Bernuth, R.D., Seginer, I., 1990. Wind considerations in sprinkler system design. Proc. Visions of the Future. Third National Irrigation Symp. ASAE, St. Joseph, MI.

Vories, E., von Bernuth, R., 1986. Single nozzle sprinkler performance in wind. Trans. ASAE 29 (5), 1325-1330.

Williamson, R.E., Threadgill, E.D., 1974. A simulation for the dynamics of evaporating spray droplets in agricultural spraying. Trans. ASAE 17 (2), 254-261. 